\title{
Quality of life of Chinese older adults receiving primary care in Wuhan, China: a multi-center study
}

\author{
Bao-Liang Zhong ${ }^{1,2}$, Yan-Min Xu ${ }^{2}$, Wu-Xiang Xie ${ }^{3}$, Xiu-Jun Liu ${ }^{\text {Corresp. } 2}$ \\ 1 Research Center for Psychological and Health Sciences, China University of Geosciences, Wuhan, Hubei Province, China \\ 2 Affiliated Wuhan Mental Health Center, Tongji Medical College of Huazhong University of Science \& Technology, Wuhan, Hubei Province, China \\ 3 Peking University Clinical Research Institute, Peking University Health Science Center, Beijing, China \\ Corresponding Author: Xiu-Jun Liu \\ Email address: yulongguowang@126.com
}

Background. Quality of life (QOL) is an important primary care outcome, but the QOL of older adults treated in primary care is understudied in China. This study examined QOL and its associated factors in older adults treated in Chinese primary care. Methods. A total of 752 older patients (65+ years) were consecutively recruited from 13 primary care centers in Wuhan, China, and interviewed with a standardized questionnaire, concerning socio-demographics, major medical conditions, loneliness, and depression. QOL and depression were measured with the Chinese six-item QOL questionnaire and the shortened Geriatric Depression Scale. Multiple linear regression was used to identify factors associated with poor QOL. Results. The average QOL score of primary care older adults was $(20.7 \pm 2.5)$, significantly lower than that of the Chinese general population. Factors significantly associated with poor QOL of Chinese primary care older adults included engaging in manual labor before older adulthood (unstandardized coefficient $[\beta]$ : -0.702 , $P<0.001)$, no living adult children $(\beta:-1.720, P=0.001)$, physical inactivity ( $\beta$ : -0.696 , $P<0.001)$, having $\geq$ four major medical conditions $(\beta:-1.813, P<0.001)$, hearing problem ( $\beta$ : $-1.004, P=0.017)$, depression $(\beta:-1.153, P<0.001)$, and loneliness $(\beta:-1.396, P<0.001)$. Conclusions. Older adults treated in Chinese primary care have poorer QOL than the general population. Addressing psychosocial problems at Chinese primary care settings could be helpful in improving QOL in Chinese older adults. 


\section{Quality of life of Chinese older adults receiving}

2 primary care in Wuhan, China: a multi-center study

3

4

5

6

7

8

Bao-Liang Zhong ${ }^{1,2}$, Yan-Min Xu ${ }^{2}$ Wu-Xiang Xie ${ }^{3}$, Xiu-Jun $\mathrm{Liu}^{2 *}$

${ }^{1}$ Research Center for Psychological and Health Sciences, China University of Geosciences, Wuhan, Hubei Province, China

${ }^{2}$ Affiliated Wuhan Mental Health Center, Tongji Medical College of Huazhong University of Science \& Technology, Wuhan, Hubei Province, China

${ }_{3}^{3}$ Peking University Clinical Research Institute, Peking University Health Science Center, Beijing, China

Corresponding Author:

Xiu-Jun $\mathrm{Liu}^{2}$

No. 89 Gongnongbing Rd., Jiangan District, Wuhan 430019, Hubei province, China Email address: yulongguowang@126.com

\section{Abstract}

Background. Quality of life (QOL) is an important primary care outcome, but the QOL of older adults treated in primary care is understudied in China. This study examined QOL and its associated factors in older adults treated in Chinese primary care.

Methods. A total of 752 older patients (65+ years) were consecutively recruited from 13 primary care centers in Wuhan, China, and interviewed with a standardized questionnaire, concerning socio-demographics, major medical conditions, loneliness, and depression. QOL and depression were measured with the Chinese six-item QOL questionnaire and the shortened Geriatric Depression Scale. Multiple linear regression was used to identify factors associated with poor QOL.

Results. The average QOL score of primary care older adults was (20.7 \pm 2.5$)$, significantly lower than that of the Chinese general population. Factors significantly associated with poor QOL of Chinese primary care older adults included engaging in manual labor before older adulthood (unstandardized coefficient $[\beta]$ : $-0.702, \mathrm{P}<0.001$ ), no living adult children $(\beta:-1.720, \mathrm{P}=0.001$ ), physical inactivity $(\beta:-0.696, P<0.001)$, having $\geq$ four major medical conditions $(\beta:-1.813$, $\mathrm{P}<0.001)$, hearing problem $(\beta:-1.004, \mathrm{P}=0.017)$, depression $(\beta:-1.153, \mathrm{P}<0.001)$, and loneliness $(\beta:-1.396, \mathrm{P}<0.001)$.

Conclusions. Older adults treated in Chinese primary care have poorer QOL than the general population. Addressing psychosocial problems at Chinese primary care settings could be helpful in improving QOL in Chinese older adults. 


\section{Introduction}

41 In China, the unprecedented social changes during the past four decades have posed significant

42 challenges to the health and well-being of older adults: decreased family size, weakened traditional family cohesion, changes in living arrangements, rapid economic growth, fast urbanization and industrialization, and massive rural-to-urban migration (Yu et al. 2016; Zhong et al. 2018a; Zhong et al. 2018b). China is ageing much faster than almost any other country in the world in recent history, and, until now, it has been the nation with the largest number of older adult population. In 2017, the total number of Chinese older adults (65+) had reached 158.31 million, over one-tenth of China's total population, and by 2050, this number will reach 336 million, nearly one-third of the total population (National Bureau of Statistics of China 2018; Zhong et al. 2016a). However, the infrastructure of China has not been prepared to meet older adults' growing needs for healthcare and social services.

To solve the contradiction between increasing demands for healthcare services and limited medical services resources, China's healthcare reform since 1994 has focused on strengthening its primary health-care system and made substantial progress (Li et al. 2017). For example, in rural regions of China, where there are insufficient healthcare resources, in 1994, 11.2\% of the villages had no any medical facilities and the average number of village doctors was 0.90 per village, while by $2017,100 \%$ of the villages had primary care clinics and the average number of village doctors had increased to 1.6 per village, respectively (Center for Statistics and Information of Ministry of Health of the People's Republic of China 1995; China National Health and Family Planning Commission. 2018). In China, because distance and transportation from home to health facility are two major determinants of older adults' preferred choice of health facility for care, $53.6 \%$ urban older adults seek treatment at community primary care centers unless they are seriously ill (Han \& Jin 2016). Due to the inconvenient transportation in rural regions, Chinese older adults living in these rural areas are more likely to seek treatment from local primary care clinics at their villages. Therefore, primary care has been very wellplaced to provide general healthcare services for Chinese older adults (Li et al. 2016; Li et al. 2017; Zhong et al. 2018b).

Although the bio-psychosocial model has dominated medical practice for many years, medical services provided by primary care in contemporary China are still quite basic and largely limited to disease treatment (Liang et al. 2018). Late life is a period when increasing numbers of 
71 psychosocial problems such as cognitive decline, depression, and loneliness are more likely to 72 occur (Zhong et al. 2017). Due to unawareness of the importance of mental health services and 73 insufficient capacity in managing psychosocial problems, Chinese older adults treated in primary 74 care have greater unmet late-life needs for psychosocial services (Sun et al. 2018). Accordingly, 75 the World Health Organization (WHO) advocated the integration of mental health services into 76 primary healthcare, particularly in low- and middle-income countries such as China (Ventevogel 77 2014).

78 Quality of life (QOL) is an important outcome measure of health-care practice, which is 79 broader than the definition of health and defined as a sense of well-being that encompasses 80 physical health, role functioning, social functioning, and psychological health (Gu et al. 2018; 81 Post 2014; Yu et al. 2016). To overcome the limitation of current disease-centered treatment in 82 Chinese primary care, it is necessary to include QOL as an important therapeutic target of 83 primary health-care. Therefore, examining QOL and its predictors in older adults treated in 84 primary care is the first necessary step towards health policy-making. However, although QOL 85 of Chinese older adults has been extensively studied, most existing studies focused on QOL of 86 community- and institution-dwelling older adults (Chen et al. 2013; Xiao et al. 2017; Zhu et al.

87 2018), and, as far as we know, few studies have investigated QOL of older adults who seek 88 treatment at Chinese primary care settings. This study was set out to investigate QOL and its 89 associated factors in older adults treated in Chinese primary care.

90

\section{Materials \& Methods}

92 Participants

93 This was part of a large-scale cross-sectional multi-center study, which investigated a range of 94 mental health outcomes, QOL, and loneliness among older primary care patients in Wuhan, 95 China, the largest metropolitan city with over ten million residents in central-south China, from 96 October 2015 to November 2016 (Zhong et al. 2018b). Wuhan is divided into 13 districts (seven 97 urban and six rural), with populations ranging from 0.21 to 1.34 million. Considering the 98 geographic representativeness of the study sample, we consciously selected one primary care 99 center from each district, which was located near the center of the most populous area of the 100 district. Older adults who were 65 years old or over and sought treatment at these primary care centers, were consecutively invited to participate in this study. We excluded older patients who 
102 were unable to complete the interview due to severe physical illnesses and severe cognitive 103 impairment, as well as those with psychotic disorders.

104 The study was approved by the Institutional Review Board of Wuhan Mental Health Center 105 (approval number: WMHC-IRB-S065). All participants provided informed consent prior to the 106 interview.

107 Procedures and instruments

108 This was a questionnaire survey. Before the main study, the questionnaire was pilot-tested and 109 finalized. The questionnaire was distributed in a face-to-face interview manner. Interviewers 110 were trained primary care physicians (PCPs) from the 13 primary care centers.

111 Demographic variables collected in the questionnaire included gender, age, education, marital 112 status, main occupation before older adult hood (mental vs. manual labor), residence location 113 (urban vs. rural), living arrangement (with family members, alone, with others), total number of 114 living adult children, smoking behavior, and physical activity.

115 Currently smoking was defined as smoking at least one cigarette per day on at least five days 116 per week (Zhong et al. 2018b). Subjects who regularly participated in physical exercise were defined as being physically active.

A checklist was used to collect data on patients' major medical conditions, which included 13 specific physical illnesses: hypertension, diabetes, heart disease, stroke and other cerebrovascular diseases, chronic obstructive pulmonary disease, cancer, tuberculosis, chronic prostatitis, chronic gastric ulcer, Parkinson's disease, anemia, hepatic sclerosis, and arthritis.

The presence of hearing and vision problems was operationally defined by the authors (Zhong et al. 2018b). Hearing problem was present if the interviewer must speak at a louder volume than usual to help the interviewee hear questions clearly, while vision problem was present if the respondent reported having difficulties in seeing TV or movies.

Depressive symptoms were assessed with the validated Chinese shortened version of Geriatric Depression Scale (GDS), which had 15 items and all were answered in a yes/no format (D'Ath et al. 1994; He et al. 2008; Liu et al. 2013). The total score of GDS ranged from zero to 15, with a cut-off score of five or more suggesting clinically significant depression.

130 In accordance with previous studies (Dahlberg et al. 2015; Victor et al. 2005; Zhong et al. 2017; Zhong et al. 2018b; Zhong et al. 2018c), feelings of loneliness were assessed with one single question: "How often do you feel lonely?". The question was responded on a five-point 
133 Likert scale: $1=$ =always, $2=$ often, $3=$ =sometimes, $4=$ seldom, $5=$ never. Loneliness was present if the 134 answer was "sometimes", "often", or "always".

135 The outcome of this study, QOL, was evaluated with the Chinese six-item QOL questionnaire 136 (Table S1), which was developed by Phillips and colleagues (Phillips et al. 2002) and has been 137 widely used to assess the QOL of various populations in China, including older adults (Dong et 138 al. 2013; Liu et al. 2013; Wu et al. 2017; Ye et al. 2013; Zhang et al. 2012). The questionnaire 139 had six questions and each assessed one domain of QOL (physical health, psychological health, 140 economic circumstances, activities, family relationship, and relationships with non-family 141 associates) on a five-point scale: $1=$ very poor, $2=$ poor, $3=$ fair, $4=$ good, $5=$ very good. The total

142 QOL score varied between six and 30, with higher score denoting better QOL. In this study, the 143 internal consistency (Cronbach $\alpha$ coefficient) of this QOL questionnaire was 0.827.

\section{Statistical analysis}

145 The average QOL score was calculated. One-sample t-test was used to compare QOL between 146 primary care older adults and the normative data, which was derived from a cross-sectional 147 survey with a very large representative sample $(n=23987)$ of Chinese general adult population in 148 2004-05 (Zhang et al. 2012). We quantified the magnitude of the difference in QOL between 149 older primary care patients and the general population with Hedges' g, a measure of standardized 150 difference between two means. Hedges' g values of $<0.50,0.50-0.80$, and $>0.80$ represent small, medium, and large differences, respectively (Zhong et al. 2019). QOL scores of different older adult cohorts according to demographic, clinical, and psychosocial characteristics were compared with independent-samples t-test or one-way analysis of variance (ANOVA) as appropriate. Multivariable linear regression analysis that entered all statistically significant variables in the above univariate analysis as independent variables and QOL score as the outcome variable was conducted to examine factors associated with QOL. Factors were selected with a backward stepwise method. Data analyses were conducted with SPSS version 17.0. The statistical significance level was set at $\mathrm{p}<0.05$ (two-sided).

\section{Results}

Altogether, 791 older adults treated in primary care were invited to join the study. Among them, 162 ten rejected, 15 were excluded due to severe cognitive impairment, six withdrew informed 
163 consent, and eight had missing values on variables of interest of the current analysis. A final 164 sample of 752 older adults were included into the current analysis.

165 Mean age of the final sample was 73.0 years (standard deviation [SD]: 6.1, range: 65-97), and 166 53.9\% were women. Other demographic, clinical, and psychosocial characteristics are displayed 167 in Table 1.

168 The average QOL score of the whole sample was 20.7 (SD: 2.5), without significant gender 169 difference (males vs. females: 20.7 [SD: 2.5] vs. 20.6 [SD: 2.5], $\mathrm{t}=0.178, \mathrm{P}=0.859$ ). Primary care 170 older adults had statistically significant lower QOL score than the normative data of Chinese 171 general population ( 20.7 vs. $23.0, \mathrm{t}=25.475, \mathrm{P}<0.001)$, which corresponded to a Hedges' $\mathrm{g}$ of 1720.85 , indicating a large magnitude of the difference in QOL between the two populations.

173 Results of univariate analysis (Table 1) show that QOL scores were significantly lower in 174 older adults who were illiterate, had marital status other than married (never-married, separated, 175 divorced, widowed, cohabitating, and remarried), engaged in physical labor before older 176 adulthood, lived alone or with others, had no living adult children, were physically inactive, 177 suffered from four or more major medical conditions, had hearing problem, were depressed, and 178 felt lonely $(\mathrm{P} \leq 0.001)$.

179 In multiple linear regression analysis (Table 2), factors significantly associated with poor QOL 180 were engaging in manual labor before older adulthood (unstandardized coefficient [ $\beta]$ : -0.702 , $181 \mathrm{P}<0.001)$, no living adult children $(\beta$ : $-1.720, \mathrm{P}=0.001)$, physical inactivity $(\beta$ : $-0.696, \mathrm{P}<0.001)$, 182 having $\geq$ four major medical conditions $(\beta$ : $-1.813, \mathrm{P}<0.001)$, hearing problem $(\beta:-1.004$, 183 $\mathrm{P}=0.017)$, depression $(\beta$ : $-1.153, \mathrm{P}<0.001)$, and loneliness $(\beta:-1.396, \mathrm{P}<0.001)$.

184

185 Discussion

186 In recent decades, QOL has been increasingly emphasized as an important health care outcome, 187 but it remains a neglected area for public policy of Chinese primary health-care system. To the 188 best of our knowledge, this is the first study investigating QOL of older adults treated in Chinese 189 primary care. In our study, a statistically poorer QOL in Chinese primary care older adults as 190 compared to the general population and the large difference in QOL between the two populations 191 were found. Because these primary care older adults all had physical illnesses, a statistically and 192 clinically poorer QOL is expected. Further, because aging is often related to a decreasing social 193 network, reduced income and poor health (Yu et al. 2016), the subjective well-being of older 
194 adults is vulnerable to functional disabilities and psychosocial problems. As evident in our study, 195 the prevalence of vision problem, depression, and loneliness in Chinese primary care older adults

196

197

198

199

200

201

202

203

204

205

206

207

208

209

210

211

212

213

214

215

216

217

218

219

220

221

222

223 were as high as $10.1 \%, 30.6 \%$, and $26.2 \%$, respectively (Table 1 ).

This study identified a number of demographic, clinical, and psychosocial factors associated with decreased QOL in older adults treated in Chinese primary care. Since older women are more likely to experience functional impairment in mobility and psychosocial problems, QOL of older adults is generally lower in women than men (Hajian-Tilaki et al. 2017). However, we found similar levels of QOL between males and females, which is possibly due to the prevailing physical illnesses of the study sample-masking the effect of gender. Previous population-based studies have reported a significant association between low socio-economic status and poor QOL (Brennan et al. 2013; Lam et al. 2017). In general, Chinese older adults who previously engaged in manual labor during their working age were often farmers and temporary workers of laborintensive factories. Because contemporary China's social security system has not been well established, the majority of these older adults are only entitled to have a very low security level of basic endowment insurance and have to rely on family members for long-term care and health care (Jiang et al. 2016; Zhong et al. 2018a). The significant link between manual labor before older adulthood and poor QOL in our study could be attributed to the low economic status of older adults who previously made their living by physical labor. In traditional Chinese culture, adult children are a major source of social support for older adults (Zhong et al. 2016b). Since social support plays an important role in buffering against the negative effects of stress, and protecting against physical and mental morbidities (Gu et al. 2018), the relationship between no living adult children and poor QOL in our study might be explained by insufficient social support to older adults without adult children.

There is clear evidence that physical activity or exercise can reduce the risk of physical and mental health problems via multiple direct and indirect mechanisms, including lowering blood pressure, decreasing risk of sarcopenia, improve physical functions and body composition, improving sleep quality, providing opportunities for increased social contacts, and changing levels serotonin and endorphins in the brain (Harris 2018; Stubbs et al. 2018; Yoo et al. 2018; Warburton \& Bredin 2017; Westbury et al. 2018). There is also supporting evidence for the beneficial effects of physical exercise on both physical and mental wellbeing (Black et al. 2015; 
224 Trachte et al. 2016). Accordingly, we found significant association of physical inactivity with 225 poor QOL of older adults treated in primary care.

226 Considering the negative effects of major medical conditions on physical QOL, and hearing 227 problem on daily functioning, the significant associations of diminished QOL with more major 228 medical conditions and hearing problem in our study are expected (Gopinath et al. 2012). The 229 theory of QOL satisfaction model argues that unmet social needs are an important cause of 230 reduced QOL (Gu et al. 2018). Consistent with this theory, loneliness was found to be 231 significantly associated with poor QOL in this study. Given the many deleterious effects of 232 depression on both physical and mental health (Zhong et al. 2015), it is reasonable to find the 233 significant association of depression with poor QOL. Overall, our findings on these physical and 234 psychosocial correlates of poor QOL are consistent with previous studies (Cao et al. 2016; Chen 235 et al. 2013; Gu et al. 2018; Zhu et al. 2018).

236 The present study has several limitations. First, this is a cross-sectional study, so the causality 237 of associations between poor QOL and its associated factors could not be ascertained.

238 Prospective studies are warranted to confirm these relationships. Second, due to our limited 239 research budget, no age- and gender-matched community-residing older adult controls were 240 recruited. QOL comparison was made with the reported normative Chinese data. Third, we 241 recruited older adults from primary care centers of only one city in China; primary care older 242 adults of other cities were not included, particularly those from economically underdeveloped 243 regions of China. We need to be cautious in generalizing our findings.

244

\section{Conclusions}

246 In summary, older adults treated in Chinese primary care have poorer QOL than the general 247 population in China. A variety of factors, particularly psychosocial problems, are significantly 248 associated with poor QOL in Chinese primary care older adults. Given that psychosocial 249 problems are preventable or modifiable, psychosocial services would be helpful for improving 250 QOL of Chinese older adults in primary care settings. The significant associations of poor QOL 251 with physical and psychosocial factors suggest that in addition to conventional disease treatment 252 for older adults, it is necessary to integrate psychosocial services into Chinese primary health253 care. 
254

255

256

257

258

259

260

261

262

263

264

265

266

267

268

269

270

271

272

273

274

275

276

277

278

279

280

281

282

283

Although primary care is a promising setting for addressing psychosocial problems of Chinese older adults, there are still barriers to providing integrated mental health services in primary care settings of China. One of the most challenging barriers was PCPs' insufficient capacity to manage psychosocial problems in China (Liang et al. 2018). Specialized educational and training programs are warranted to strengthen PCPs' ability to recognize, diagnose, manage and refer older patients with psychosocial problems and mental disorders. To improve older patients' physical and mental wellbeing, it is also necessary to train PCPs to acquire basic skills for psychosocial supports and health education. Considering the association between physical inactivity and poor QOL, PCPs should be aware of the negative effects of unhealthy lifestyle on the health and QOL of older adults and encourage their older patients to do appropriate physical activities such as Tai Chi and other traditional Chinese activities.

\section{Acknowledgements}

The authors thank all the research staff for their team collaboration work and all the primary care physicians and older adults involved in this study for their cooperation and support.

\section{References}

Black SV, Cooper R, Martin KR, Brage S, Kuh D, and Stafford M. 2015. Physical Activity and Mental Well-being in a Cohort Aged 60-64 Years. Am J Prev Med 49:172-180.

Brennan SL, Williams LJ, Berk M, and Pasco JA. 2013. Socioeconomic status and quality of life in population-based Australian men: data from the Geelong Osteoporosis Study. Aust NZ J Public Health 37:226-232.

Cao W, Guo C, Ping W, Tan Z, Guo Y, and Zheng J. 2016. A Community-Based Study of Quality of Life and Depression among Older Adults. Int J Environ Res Public Health 13.

Center for Statistics and Information of Ministry of Health of the People's Republic of China. 1995. Chinese statistical bulletin on health development in 1994. Chin Health Policy 6:68.

Chen Y, Hicks A, and While AE. 2013. Quality of life of older people in China: a systematic review. Rev Clin Gerontol 23:88-100. 
284 China National Health and Family Planning Commission. 2018. The 2017 statistical bulletin on

285

286

287

288

289

290

291

292

293

294

295

296

297

298

299

300

301

302

303

304

305

306

307

308

309

310

311

312

313

314 development of China health and family planning career. Available at http://www.nhfpc.gov.cn/guihuaxxs/s10743/201806/44e3cdfel1fa4c7f928c879d435b6a18.s html (accessed 10-January 2019).

D'Ath P, Katona P, Mullan E, Evans S, and Katona C. 1994. Screening, detection and management of depression in elderly primary care attenders. I: The acceptability and performance of the 15 item Geriatric Depression Scale (GDS15) and the development of short versions. Fam Pract 11:260-266.

Dahlberg L, Andersson L, McKee KJ, and Lennartsson C. 2015. Predictors of loneliness among older women and men in Sweden: A national longitudinal study. Aging Ment Health 19:409-417.

Dong M, Zhang J, Lu C, Tang J, Liu L, Qiu H, Wang S, Wang A, and Li X. 2013. A case-control study on the quality of life and the way of response among patients with anxiety disorder in Shangdong province. Chin J Epidemiol 34:953-957.

Gopinath B, Schneider J, McMahon CM, Teber E, Leeder SR, and Mitchell P. 2012. Severity of age-related hearing loss is associated with impaired activities of daily living. Age Ageing 41:195-200.

Gu W, Xu YM, and Zhong BL. 2018. Health-related quality of life in Chinese inpatients with lung cancer treated in large general hospitals: a cross-sectional study. BMJ Open 8:e019873.

Hajian-Tilaki K, Heidari B, and Hajian-Tilaki A. 2017. Are Gender Differences in Health-related Quality of Life Attributable to Sociodemographic Characteristics and Chronic Disease Conditions in Elderly People? Int J Prev Med 8:95.

Han X, and Jin X. 2016. Analysis of treatment seeking behaviors and influencing factors of old people in Wuhan. Medicine and Society 29:56-59.

Harris MA. 2018. The relationship between physical inactivity and mental wellbeing: Findings from a gamification-based community-wide physical activity intervention. Health Psychol Open 5:2055102917753853.

He X, Xiao S, and Zhang D. 2008. Reliability and validity of the Chinese version of Geriatric Depression Scale: a study in a population of Chinese rural community-dwelling elderly. Chin J Clin Psychol 16:473-475, 543. 
315 Jiang Q, Yang S, Sánchez-Barricarte JJ. 2016. Can China afford rapid aging? Springerplus $316 \quad 5: 1107$.

317 Lam CLK, Guo VY, Wong CKH, Yu EYT, and Fung CSC. 2017. Poverty and health-related 318 income families and the general population. $J$ Public Health (Oxf) 39:258-265.

Li T, Lei T, Xie Z, and Zhang T. 2016. Determinants of basic public health services provision by village doctors in China: using non-communicable diseases management as an example. BMC Health Serv Res 16:42.

Li X, Lu J, Hu S, Cheng KK, De Maeseneer J, Meng Q, Mossialos E, Xu DR, Yip W, Zhang H Krumholz HM, Jiang L, and Hu S. 2017. The primary health-care system in China. Lancet 390:2584-2594.

Liang D, Mays VM, and Hwang WC. 2018. Integrated mental health services in China: challenges and planning for the future. Health Policy Plan 33:107-122.

Liu J, Wang Y, Wang X, Song R, and Yi X. 2013. Reliability and validlity of the Chinese version of Geriatric Depression Scale among Chinese urban community-dwelling elderly population. Chin J Clin Psychol 21:39-41.

National Bureau of Statistics of China. 2018. 2018 China Population \& Employment Statistics Yearbook. Beijing: China Statistics Press.

Phillips MR, Yang G, Zhang Y, Wang L, Ji H, and Zhou M. 2002. Risk factors for suicide in China: a national case-control psychological autopsy study. Lancet 360:1728-1736.

Post MW. 2014. Definitions of quality of life: what has happened and how to move on. Top Spinal Cord Inj Rehabil 20:167-180.

Stubbs B, Vancampfort D, Hallgren M, Firth J, Veronese N, Solmi M, Brand S, Cordes J, Malchow B, Gerber M, Schmitt A, Correll CU, De Hert M, Gaughran F, Schneider F, Kinnafick F, Falkai P, Möller HJ, and Kahl KG. 2018. EPA guidance on physical activity as a treatment for severe mental illness: a meta-review of the evidence and Position Statement from the European Psychiatric Association (EPA), supported by the International Organization of Physical Therapists in Mental Health (IOPTMH). Eur Psychiatry 54:124-144.

Sun KS, Lam TP, and Wu D. 2018. Chinese perspectives on primary care for common mental disorders: Barriers and policy implications. Int J Soc Psychiatry 64:417-426. 
346 Trachte F, Geyer S, and Sperlich S. 2016. Impact of physical activity on self-rated health in older 347 people: do the effects vary by socioeconomic status? J Public Health (Oxf) 38:754-759.

348 349

350 351

352 353

354

355

356

357

358

359

360

361

362

363

364

365

366

367

368

369

370

371

372

373

374

375

376

Ventevogel P. 2014. Integration of mental health into primary healthcare in low-income countries: avoiding medicalization. Int Rev Psychiatry 26:669-679.

Victor C, Grenade L, and Boldy D. 2005. Measuring loneliness in later life: a comparison of differing measures. Reviews in Clinical Gerontology 15:63-70.

Warburton DER, and Bredin SSD. 2017. Health benefits of physical activity: a systematic review of current systematic reviews. Curr Opin Cardiol 32:541-556.

Westbury LD, Dodds RM, Syddall HE, Baczynska AM, Shaw SC, Dennison EM, Roberts HC, Sayer AA, Cooper C, and Patel HP. 2018. Associations Between Objectively Measured Physical Activity, Body Composition and Sarcopenia: Findings from the Hertfordshire Sarcopenia Study (HSS). Calcif Tissue Int 103:237-245

Wu S, Ding L, Liao Z, and Chen Y. 2017. A case-control study on the quality of life and social function among patients with mood disorders. Contemp Med 23:3-8.

Xiao H, Yoon JY, and Bowers B. 2017. Quality of life of nursing home residents in China: A mediation analysis. Nurs Health Sci 19:149-156.

Ye M, Zhong S, Lin C, Ye S, and Chen C. 2013. Prevalence, influencing factors and helpseeking style of depression among elderly population in Wenzhou area. Chin J Public Health 29:8-11.

Yoo SZ, No MH, Heo JW, Park DH, Kang JH, Kim SH, and Kwak HB. 2018. Role of exercise in age-related sarcopenia. J Exerc Rehabil 14:551-558.

Yu L, Yan Z, Yang X, Wang L, Zhao Y, and Hitchman G. 2016. Impact of Social Changes and Birth Cohort on Subjective Well-Being in Chinese Older Adults: A Cross-Temporal Meta-analysis, 1990-2010. Social Indicators Research 126:795-812.

Zhang S, Yu D, Wang J, Zhao X, Yue K, Liu F, Yu Y, Jiang X, Jiang Y, Zhao C, Hu B, and Cao X. 2012. A cross-sectional study about prevalence of schizophrenia, life qualities, coping styles and social functions in people above 18 years old in Shandong Province. $J$ Psychiatry 25:168-171.

Zhong BL, Chen SL, Tu X, and Conwell Y. 2017. Loneliness and Cognitive Function in Older Adults: Findings From the Chinese Longitudinal Healthy Longevity Survey. J Gerontol B Psychol Sci Soc Sci 72:120-128.

Peer] reviewing PDF | (2019:01:34439:2:0:NEW 21 Mar 2019) 
377 Zhong BL, Chiu HF, and Conwell Y. 2016a. Elderly suicide trends in the context of 378 transforming China, 1987-2014. Sci Rep 6:37724.

379 Zhong BL, Chiu HF, and Conwell Y. 2016b. Rates and characteristics of elderly suicide in China, 380 2013-14. J Affect Disord 206:273-279.

381 Zhong BL, Liu TB, Chan SS, Jin D, Hu CY, Dai J, and Chiu HF. 2015. Prevalence and correlates 382 of major depressive disorder among rural-to-urban migrant workers in Shenzhen, China.

383

384 385

386

387 388 389

390

391

392

393

394

395

396

397 J Affect Disord 183:1-9.

Zhong BL, Liu TB, Chan SS, Jin D, Hu CY, Dai J, and Chiu HF. 2018a. Common mental health problems in rural-to-urban migrant workers in Shenzhen, China: prevalence and risk factors. Epidemiol Psychiatr Sci 27:256-265.

Zhong BL, Liu XJ, Chen WC, Chiu HF, and Conwell Y. 2018b. Loneliness in Chinese older adults in primary care: prevalence and correlates. Psychogeriatrics 18:334-342.

Zhong BL, Xu YM, Zhu JH, and Liu XJ. 2018c. Non-suicidal self-injury in Chinese heroindependent patients receiving methadone maintenance treatment: Prevalence and associated factors. Drug Alcohol Depend 189:161-165.

Zhong BL, Xu YM, Xie WX, and Li Y. 2019. Can P300 aid in the differential diagnosis of unipolar disorder versus bipolar disorder depression? A meta-analysis of comparative studies. J Affect Disord 245:219-227.

Zhu Y, Liu J, Qu B, and Yi Z. 2018. Quality of life, loneliness and health-related characteristics among older people in Liaoning province, China: a cross-sectional study. BMJ Open 8:e021822.

398 


\section{Table $\mathbf{1}$ (on next page)}

Characteristics of Chinese older adults treated in primary care and quality of life (QOL) scores by variable 
1 Table 1. Characteristics of Chinese older adults treated in primary care and quality of life (QOL) scores by

2 variable

\begin{tabular}{|c|c|c|c|c|c|c|}
\hline \multicolumn{2}{|c|}{ Characteristics } & \multirow{2}{*}{$\begin{array}{c}\begin{array}{c}\text { Number of } \\
\text { older adults }\end{array} \\
347\end{array}$} & \multirow{2}{*}{$\begin{array}{c}\% \\
46.1\end{array}$} & \multirow{2}{*}{$\begin{array}{l}\text { QOL score (mean } \pm \\
\text { standard deviation) } \\
20.7 \pm 2.5\end{array}$} & \multirow{3}{*}{$\begin{array}{c}\mathrm{t} / \mathrm{F} \\
0.178\end{array}$} & \multirow{3}{*}{$\begin{array}{c}P \\
0.859\end{array}$} \\
\hline Gender & Male & & & & & \\
\hline & Female & 405 & 53.9 & $20.6 \pm 2.5$ & & \\
\hline \multirow[t]{2}{*}{ Age (years) } & $65-74$ & 484 & 64.4 & $20.7 \pm 2.5$ & \multirow{2}{*}{1.263} & \multirow{2}{*}{0.207} \\
\hline & $75+$ & 268 & 35.6 & $20.5 \pm 2.6$ & & \\
\hline \multirow[t]{4}{*}{ Education } & Illiterate & 177 & 23.5 & $20.1 \pm 2.5$ & \multirow{4}{*}{10.974} & \multirow{4}{*}{$<0.001$} \\
\hline & Primary school & 213 & 28.3 & $20.3 \pm 2.4$ & & \\
\hline & $\begin{array}{l}\text { Junior middle } \\
\text { school }\end{array}$ & 212 & 28.2 & $20.9 \pm 2.4$ & & \\
\hline & $\begin{array}{l}\text { Senior middle } \\
\text { school and above }\end{array}$ & 150 & 19.9 & $21.5 \pm 2.6$ & & \\
\hline \multirow[t]{2}{*}{ Marital status } & Married & 534 & 71.0 & $20.9 \pm 2.4$ & \multirow{2}{*}{3.414} & \multirow{2}{*}{0.001} \\
\hline & Others* & 218 & 29.0 & $20.2 \pm 2.7$ & & \\
\hline \multirow{2}{*}{$\begin{array}{l}\text { Main occupation before } \\
\text { older adulthood }\end{array}$} & Mental labor & 216 & 28.7 & $21.4 \pm 2.5$ & \multirow{2}{*}{5.461} & \multirow{2}{*}{$<0.001$} \\
\hline & Manual labor & 536 & 71.3 & $20.3 \pm 2.5$ & & \\
\hline \multirow[t]{2}{*}{ Residence place } & Urban & 403 & 53.6 & $20.7 \pm 2.6$ & \multirow{2}{*}{0.905} & \multirow{2}{*}{0.366} \\
\hline & Rural & 349 & 46.4 & $20.6 \pm 2.4$ & & \\
\hline \multirow[t]{3}{*}{ Living arrangement } & $\begin{array}{l}\text { With family } \\
\text { members }\end{array}$ & 637 & 84.7 & $20.8 \pm 2.5$ & \multirow{3}{*}{15.229} & \multirow{3}{*}{$<0.001$} \\
\hline & Alone & 81 & 10.8 & $20.1 \pm 2.6$ & & \\
\hline & With others & 34 & 4.5 & $19.2 \pm 2.1$ & & \\
\hline \multirow{2}{*}{$\begin{array}{l}\text { Number of living adult } \\
\text { children }\end{array}$} & 0 & 19 & 2.5 & $17.7 \pm 2.2$ & \multirow{2}{*}{5.854} & \multirow{2}{*}{$<0.001$} \\
\hline & $\geq 1$ & 733 & 97.5 & $20.7 \pm 2.5$ & & \\
\hline \multirow[t]{2}{*}{ Currently smoking } & No & 631 & 83.9 & $20.6 \pm 2.5$ & \multirow{2}{*}{0.283} & \\
\hline & Yes & 121 & 16.1 & $20.7 \pm 2.5$ & & נוז. \\
\hline Physically active & No & 326 & 43.4 & $20.1 \pm 2.6$ & 5.447 & $<0.001$ \\
\hline & Yes & 426 & 56.6 & $21.1 \pm 2.4$ & & \\
\hline Number of major medical & $\leq 3$ & 680 & 90.4 & $20.9 \pm 2.5$ & 9695 & $<0001$ \\
\hline conditions & $\geq 4$ & 72 & 9.6 & $18.7 \pm 1.7$ & 9.053 & $<0.001$ \\
\hline Hearing problem & No & 722 & 96.0 & $20.7 \pm 2.5$ & 3335 & O०01 \\
\hline & Yes & 30 & 4.0 & $19.2 \pm 2.5$ & כ3.כ. & 0.001 \\
\hline Vision problem & No & 676 & 89.9 & $20.9 \pm 2.5$ & 1050 & 0.294 \\
\hline & Yes & 76 & 10.1 & $20.6 \pm 2.5$ & 1.050 & 0.294 \\
\hline Depressive symptoms & No & 522 & 69.4 & $21.2 \pm 2.3$ & 8898 & $<0001$ \\
\hline & Yes & 230 & 30.6 & $19.4 \pm 2.6$ & 0.050 & $=0.001$ \\
\hline Loneliness & No & 555 & 73.8 & $21.2 \pm 2.2$ & 9524 & $<0,001$ \\
\hline & Yes & 197 & 26.2 & $19.1 \pm 2.8$ & & \\
\hline
\end{tabular}

3 *"Others" included never-married, separated, divorced, widowed, cohabitating, and remarried. 


\section{Table 2 (on next page)}

Multiple linear regression of factors significantly associated with poor quality of life 
Table 2. Multiple linear regression of factors significantly associated with poor quality of life

\begin{tabular}{lcccccc}
\hline \multicolumn{1}{c}{ Variable } & Risk level & $\begin{array}{c}\text { Reference } \\
\text { level }\end{array}$ & Coefficient & $\begin{array}{c}\text { Standard } \\
\text { error }\end{array}$ & t & P \\
\hline $\begin{array}{l}\text { Main occupation before older } \\
\text { adulthood }\end{array}$ & Manual labor & Mental labor & -0.702 & 0.176 & $3.986<0.001$ \\
$\begin{array}{l}\text { Number of living adult children } \\
\text { Physically active }\end{array}$ & 0 & $\geq 1$ & -1.720 & 0.510 & 3.372 & 0.001 \\
Number of major medical & No & Yes & -0.696 & 0.163 & $4.279<0.001$ \\
$\begin{array}{l}\text { conditions } \\
\text { Hearing problem }\end{array}$ & $\geq 4$ & $\leq 3$ & -1.813 & 0.281 & 6.457 & $<0.001$ \\
Depressive symptoms & Yes & No & -1.004 & 0.421 & 2.384 & 0.017 \\
Loneliness & Yes & No & -1.153 & 0.180 & 6.420 & $<0.001$ \\
\hline
\end{tabular}

2 